\title{
Removal of pollutants with determination of power consumption from landfill leachate wastewater using an electrocoagulation process: optimization using response surface methodology (RSM)
}

\author{
Perumal Asaithambi, ${ }^{1,2} \cdot$ Dejene Beyene $^{1} \cdot$ Abdul Raman Abdul Aziz $^{2} \cdot$ Esayas Alemayehu $^{1}$
}

Received: 26 November 2017 / Accepted: 13 April 2018 / Published online: 23 April 2018

(c) The Author(s) 2018

\begin{abstract}
Treatment of landfill leachate wastewater by electrocoagulation process using an aluminium electrode was investigated in a batch electrochemical cell reactor. Response surface methodology based on central composite design was used to optimize the operating parameters for the removal of $\%$ color and $\%$ total organic carbon (TOC) together with power consumption from landfill leachate. Effects of three important independent parameters such as current density $\left(X_{1}\right)$, inter-electrode distance $\left(X_{2}\right)$ and solution $\mathrm{pH}\left(X_{3}\right)$ of the landfill leachate sample on the $\%$ color and $\%$ TOC removal with power consumption were investigated. A quadratic model was used to predict the $\%$ color and $\%$ TOC removal with power consumption in different experimental conditions. The significance of each independent variable was calculated by analysis of variance. In order to achieve the maximum $\%$ color and $\%$ TOC removal with minimum of power consumption, the optimum conditions were about current density $\left(X_{1}\right)-5.25 \mathrm{~A} / \mathrm{dm}^{2}$, inter-electrode distance $\left(X_{2}\right)-1 \mathrm{~cm}$ and initial solution of effluent $\mathrm{pH}\left(X_{3}\right)-7.83$, with the yield of color removal of $74.57 \%$, and TOC removal of $51.75 \%$ with the power consumption of $14.80 \mathrm{kWh} / \mathrm{m}^{3}$. Electrocoagulation process could be applied to remove pollutants from industrial effluents and wastewater.
\end{abstract}

Keywords Electrocoagulation $\cdot$ Landfill leachate $\cdot$ Color and TOC removal $\cdot$ Power consumption $\cdot$ Central composite design

\section{Introduction}

Increases in world population and new patterns of consumption have resulted in huge production of wastes that are usually discarded in sanitary landfills, since this is relatively simple and inexpensive (Azni 2009). Landfill leachate wastewater can be generated from precipitation, surface run-off, infiltration or intrusion of groundwater percolating though the landfill (Li et al. 2011). Various types of pollutants can be found in sanitary landfill leachate such as organic and

Perumal Asaithambi

drasaithambi2014@gmail.com

Esayas Alemayehu

esayas16@yahoo.com

1 Faculty of Civil and Environmental Engineering, Jimma Institute of Technology, Jimma University, Po Box 378, Jimma, Ethiopia

2 Department of Chemical Engineering, Faculty of Engineering, University of Malaya, 50603 Kuala Lumpur, Malaysia inorganic compounds, toxic and heavy metals (Fernandes et al. 2015). Due to its complex and recalcitrant composition, the sanitary landfill leachate represents a significant source of pollutants. Discharge of the landfill leachate into the environment can have a detrimental effect on aquatic life, cause infertility of soil and mutagenic effect on humans as well as affecting the ecological balance. The treatment of landfill leachate wastewater is difficult due to the discharge standards, variable composition and its high pollutant load. Several treatment methods have been used to treat the landfill leachate, such as biological processes ( $\mathrm{Li}$ et al. 2017; Zhang et al. 2016; Robinson. 2017), membrane processes (Ahn et al. 2002), coagulation and flocculation methods (Wang et al. 2015; Liu et al. 2012), flotation methods (Adlan et al. 2011), adsorption and chemical precipitation (Hur and Kim 2000; Erabee et al. 2017), osmosis (Iskander et al. 2017), chemical oxidation (Derco et al. 2010), Fenton and electrochemical (Vallejo et al. 2012), advanced oxidation techniques $\mathrm{Hu}$ et al. 2011; Zhang et al. 2012; Chys et al. 2015) and electro-Fenton (Zhang et al. 2014). However, these methods are found to have certain shortages such 
as operating cost, transfer of one phase to another, lower pollutant removal efficiency and decreasing the process performance. Thus, it is essential to design and develop an economic and effective treatment method for removing pollutants from landfill leachate wastewater.

Electrochemical processes have shown high effectiveness in eliminating persistent pollutants from landfill leachate wastewater (Ricordel and Djelal 2014; Panizza et al. 2010) and have some advantages such as energy efficiency, versatility and cost-effectiveness (Juttner et al. 2000). Among the electrochemical methods, electrocoagulation process appears to be the most effective substitution for the conventional coagulation and flotation process as it can deal with pollutants with a variety of compositions (Wang et al. 2009; Butler et al. 2017).

Electrocoagulation is a simple process in terms of its equipment setup and easy-to-handle methodology, high efficiency with production of less sludge (Kalyani et al. 2009; Sharma and Chopra 2017). It can be operated at ambient temperature and pressure. Electrocoagulation is an electrolytic process involving the dissolution of the sacrificial anodes, made of aluminium (Al), upon application to a current between the two electrodes to supply ions to the wastewater, allowing suspended, emulsified or dissolved contaminants to form agglomerates (Fernandes et al. 2015). The coagulating ions are produced in situ and the successive stages for current theory of electrocoagulation are described as follows: firstly, the formation of coagulants induced by the electrolytic oxidation of the sacrificial anode followed by generation of metal hydroxides; secondly, destabilization of the contaminants and particulate suspension and breaking of emulsions; and lastly, the aggregation or coalescence of the destabilized phases to form larger and separable agglomerates (Moreno-Casillas et al. 2007). Hydrogen $\left(\mathrm{H}_{2}\right)$ bubbles that evolve from the cathode surface are adsorbed onto the suspended particles. The separation of the solid matter is achieved either by flotation upon the adsorption of $\mathrm{H}_{2}$ bubbles, or allowing the solid to settle down due to its higher density which the buoyant force produced by the $\mathrm{H}_{2}$ bubbles is insufficient to lift the suspended solid (Zodi et al. 2009). The mechanism of electrocoagulation process depends on the chemistry of the aqueous medium, especially the conductivity. The mechanism of ion formation is proposed as in Eqs. (1)-(4) below using aluminium electrode (Fernandes et al. 2015).

Anodic reaction:

$$
\mathrm{Al}_{(\mathrm{s})} \rightarrow \mathrm{Al}_{(\mathrm{aq})}^{3+}+3 \mathrm{e}^{-}
$$

Cathodic reaction:

$$
2 \mathrm{H}_{2} \mathrm{O}_{(\mathrm{l})}+2 \mathrm{e}^{-} \rightarrow \mathrm{H}_{2(\mathrm{~g})}+2 \mathrm{OH}_{(\mathrm{aq})}^{-}
$$

Chemical reaction that takes place in the aqueous medium:

$\mathrm{Al}_{(\mathrm{aq})}^{3+}+\mathrm{OH}_{(\mathrm{aq})}^{-} \rightarrow \mathrm{Al}(\mathrm{OH})_{3(\mathrm{~s})}$

Overall reaction is given by:

$\mathrm{Al}_{(\mathrm{aq})}^{3+}+3 \mathrm{H}_{2} \mathrm{O}_{(\mathrm{l})} \rightarrow \mathrm{Al}(\mathrm{OH})_{3(\mathrm{~s})}+3 \mathrm{H}_{(\mathrm{aq})}^{+}$

Based on the literature review, many studies on the electrocoagulation process were carried out by varying one factor while the other factors are kept constant (Chopra and Sharma 2013; Sharma and Chopra 2017). However, this approach consumes more time and response surface methodology (RSM) can be an alternative to overcome this problem. Most of the previous studies only focused on the performance of electrocoagulation process such as $\%$ COD and \% color removal (Saravanan et al. 2010; Janpoor et al. 2011), but did not emphasize on the \% TOC removal with power consumption. It was important to determine the power consumption of electrocoagulation process in order to determine its operating cost and feasibility. The objective of this research work is to identify the optimum operating parameters for the removal of pollutants from landfill leachate using central composite design (CCD).

RSM is used to optimize the parameters chosen for the electrocoagulation process. It is a regression analysis used to predict the value of dependent variable based on the controlled values of independent variables. Numerous experiment combinations can be generated within a short period of time, thus allowing researchers to know whether the tested parameter has a significant impact on the research work (Liu et al. 2012; Butler et al. 2017). In many technical fields, it is common that the output variable $(Y)$ exists with a set of predicted variables or the input variables $\left(X_{1}, X_{2}, X_{3}, \ldots X_{k}\right)$. The output variable is a function of input variable together with the error presence in the model, usually written as $Y=f\left(X_{1}, X_{2}, X_{3}, \ldots X_{k}\right)+\in$, where $f$ is the unknown surface response which is normally described by a first-order or second-order polynomial, while $\in$ is the error in the model. Generally, the first- and second-order models are given as in Eqs. (5) and (6):

$Y=\beta_{o}+\sum_{j=1}^{k} \beta_{j} X_{j}+\epsilon$

$Y=\beta_{o}+\sum_{j=1}^{k} \beta_{j} X_{j}+\sum_{j=1}^{k} \beta_{j j} X_{j}^{2}+\sum_{j=1}^{k-1} \sum_{i=2}^{k} \beta_{j i} X_{j} X_{i}+\epsilon_{i}$

where $X_{i}$ and $X_{j}$ are coded independence variables and $\beta_{j}$, $\beta_{j j}$, and $\beta_{j i}(i=1,2, \ldots, k ; j=1,2, \ldots, k)$ are the regression coefficients. A first-order model is used to describe 
the flat surface, while the curve surface is described by a second-order model, or also known as a quadratic model. A quadratic model is often adequate for RSM in most cases. Besides, the knowledge of statistical fundamentals, regression modeling techniques and optimization methods is required in fitting the response surface model.

The main objective of optimization was to maximize the $\%$ color and \% TOC removal while minimizing the power consumption by varying operating parameters such as current density $\left(X_{1}\right)$, inter-electrode distance $\left(X_{2}\right)$ and initial pH $\left(X_{3}\right)$. Design of Expert (DoE) Software (11) was used to optimize and study the combined effect of three selected parameters. Each independent variable was coded at three levels between -1 and +1 , where the variables current density $\left(X_{1}\right)$, inter-electrode distance $\left(X_{2}\right)$ and initial effluent $\mathrm{pH}$ $\left(X_{3}\right)$ were set in the range of $1.05-6.25 \mathrm{~A} / \mathrm{dm}^{2}, 1.0-4.0 \mathrm{~cm}$, and $\mathrm{pH} 5-11$, respectively, as indicated in Table 1.

\section{Materials and methods}

\section{Materials}

Landfill leachate wastewater was collected from Jeram sanitary landfill, Selangor, Malaysia. Various parameters such as $\mathrm{pH}$, chemical oxygen demand (COD), total organic carbon (TOC), color and odor were analyzed and tabulated in Table 2. COD was measured by closed reflux method using potassium dichromate (Spectroquant ${ }^{\circledR}$ TR320); TOC was measured using the TOC analyzer (TOC-LCSH/CPH) and color was determined using UV/Vis spectrophotometer (Spectroquant Pharo ${ }^{\circledR} 300$ ). Chemicals such as $\mathrm{K}_{2} \mathrm{Cr}_{2} \mathrm{O}_{7}$, $\mathrm{NaCl}, \mathrm{H}_{2} \mathrm{SO}_{4}, \mathrm{NaOH}$, etc., were used and supplied from YEW SII SIE lab analytics supplies, Malaysia.

\section{Methods}

Experimental setup for the electrocoagulation process is shown in Fig. 1. Experiment was carried out in a batch reactor with a capacity of $500 \mathrm{~mL}$ (YEW SII SIE lab analytics supplies, Malaysia). Initial COD concentration of the landfill leachate wastewater was diluted into $1500 \mathrm{ppm}$. Aluminium

Table 1 Coded and actual values of the variables of the design of experiments for the electrocoagulation process

\begin{tabular}{llllll}
\hline Variable & Unit & Factor & \multicolumn{2}{l}{ Levels } \\
\cline { 3 - 6 } & & & -1 & 0 & 1 \\
\hline Current density & $\mathrm{A} / \mathrm{dm}^{2}$ & $X_{1}$ & 1.05 & 3.65 & 6.25 \\
Inter-electrode distance & $\mathrm{cm}$ & $X_{2}$ & 1.0 & 2.50 & 4.0 \\
Initial effluent $\mathrm{pH}$ & - & $X_{3}$ & 5 & 8 & 11 \\
\hline
\end{tabular}

Table 2 Characterization of landfill leachate wastewater

\begin{tabular}{ll}
\hline Parameter & Value \\
\hline COD $(\mathrm{mg} / \mathrm{L})$ & 7225 \\
TOC $(\mathrm{mg} / \mathrm{L})$ & 4000 \\
Absorbance $(\mathrm{Au})$ & 4.534 \\
$\mathrm{pH}$ & 8.1 \\
Color & Dark brown \\
Smell & Pungent ammonia smell \\
Temperature $\left({ }^{\circ} \mathrm{C}\right)$ & 33 \\
Turbidity $(\mathrm{NTU})$ & 230 \\
\hline
\end{tabular}

(Al) electrodes with dimension of $16 \mathrm{~cm} \times 6 \mathrm{~cm}$ were used for both anode and cathode. The effective electrode surface area was $48 \mathrm{~cm}^{2}$ and the inter-electrode distance between an anode and cathode was varied from 1 to $4 \mathrm{~cm}$. The $\mathrm{pH}$ of the landfill leachate was measured by $\mathrm{pH}$ meter (Elico; Model LI120) and varied from pH 5 to 11 using $\mathrm{H}_{2} \mathrm{SO}_{4}$ and $\mathrm{NaOH}$ solutions. The electrodes were connected to a direct current (DC) power supply (APLAB Ltd; Model L1606) with aid of crocodile clips for supplying constant current density, varying from 1.05 to $6.25 \mathrm{~A} / \mathrm{dm}^{2} .3 \mathrm{~g} / \mathrm{L} \mathrm{NaCl}$ was added in the solution to improve the electrical conductivity of the solution and a magnetic stirrer was used at $500 \mathrm{rpm}$ to increase the probability of particle collision to improve the efficiency of the electrocoagulation process. After the required experimental condition, sample was taken after $1 \mathrm{~h}$ of electrolysis time and the filtered using filter paper. Then, the sample was immediately analyzed for color and TOC removal. The removal of the color was determined using the UV/Vis spectrophotometer (Spectroquant ${ }^{\circledR}$ TR320) and TOC was determined using the TOC analyzer (TOC-LCSH/ $\mathrm{CPH})$.

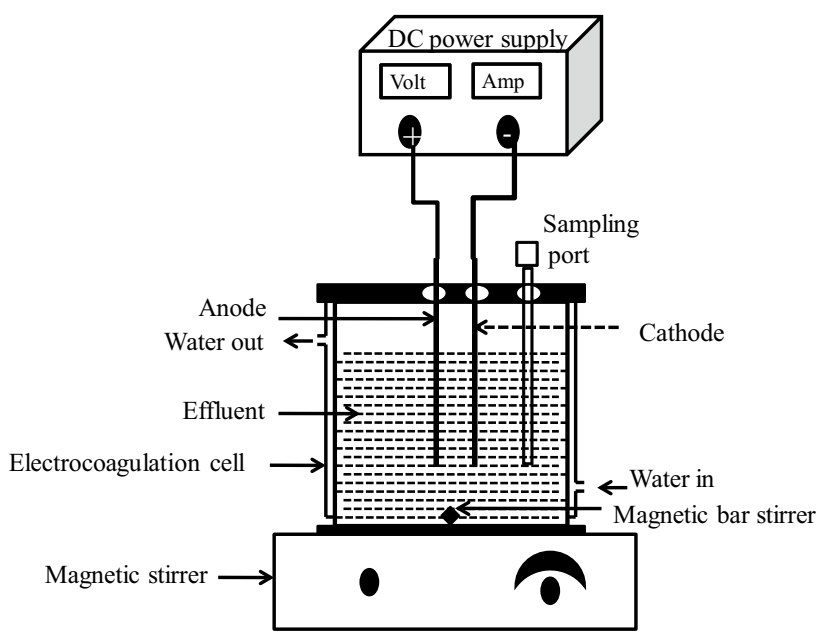

Fig. 1 Experimental setup for the electrochemical process 


\section{Analysis}

\section{Color and TOC removal (\%)}

The $\%$ color and $\%$ TOC removal were calculated using Eqs. (7) and (8):

Color removal efficiency $(\%)=\frac{\left(\left[\mathrm{Abs}_{i}\right]\right)-\left(\left[\mathrm{Abs}_{t}\right]\right)}{\mathrm{Abs}_{i}} \times 100$

where $\mathrm{Abs}_{i}$ and $\mathrm{Abs}_{t}$ are absorbance of samples at initial and reaction time $t$ for a corresponding wavelength $\lambda_{\max }$.

TOC removal efficiency $(\%)=\frac{\left(\left[\mathrm{TOC}_{i}\right]\right)-\left(\left[\mathrm{TOC}_{t}\right]\right)}{\mathrm{TOC}_{i}} \times 100$

where $\mathrm{TOC}_{i}$ is the initial of TOC and $\mathrm{TOC}_{t}$ is the TOC at any reaction time, $t(\mathrm{mg} / \mathrm{L})$.

\section{Power consumption}

The power consumption for the removal of $\%$ color and $\%$ TOC from landfill leachate using the electrocoagulation process was calculated using Eq. (9):

$P=\frac{\mathrm{VIt}}{V_{\mathrm{R}}},\left(\frac{\mathrm{kWhr}}{\mathrm{m}^{3}}\right)$ where $V$ is the cell voltage $(\mathrm{V}), I$ is the applied current (A), $t$ is the electrolysis time (h) and $V_{\mathrm{R}}$ is the volume of wastewater used $\left(\mathrm{m}^{3}\right)$.

\section{Results and discussion}

\section{Central composite design}

A 3-factor and 3-level CCD was used to optimize the operating parameters of an electrocoagulation process on the responses such as the \% color and \% TOC removal efficiency as well as the power consumption. The total number of experiment combinations was 20, with 6 replications at the design central to determine the pure error. The total number of runs, experimental conditions, response of $\%$ color removal, \% TOC removal and power consumption together with the predicted values are shown in Table 3.

\section{Evaluation of experimental results with design of experiments}

The \% color removal $\left(Y_{1}\right), \%$ TOC removal $\left(Y_{2}\right)$ and power consumption $\left(Y_{3}\right)$ are the function of operating parameters such as current density $\left(X_{1}\right)$, inter-electrode distance $\left(X_{2}\right)$ and initial $\mathrm{pH}\left(X_{3}\right)$ at constant electrolysis time of $1 \mathrm{~h}$. The
Table 3 Experimental design matrix and response based on the experimental runs and predicted values on the color removal (\%), TOC removal (\%) and power consumption proposed by the CCD

\begin{tabular}{|c|c|c|c|c|c|c|c|c|c|}
\hline \multirow[t]{2}{*}{ Run } & \multirow{2}{*}{$\begin{array}{l}X_{1} \\
\mathrm{~A} / \mathrm{dm}^{2}\end{array}$} & \multirow{2}{*}{$\begin{array}{l}X_{2} \\
\mathrm{~cm}\end{array}$} & \multirow{2}{*}{$\begin{array}{l}X_{3} \\
-\end{array}$} & \multicolumn{2}{|c|}{ Color removal (\%) } & \multicolumn{2}{|c|}{ TOC removal (\%) } & \multicolumn{2}{|c|}{$\begin{array}{l}\text { Power consumption } \\
\left(\mathrm{kWhr} / \mathrm{m}^{3}\right)\end{array}$} \\
\hline & & & & Actual & Predicted & Actual & Predicted & Actual & Predicted \\
\hline 1 & 1.05 & 1 & 5 & 45.25 & 46.67 & 33.5 & 33.36 & 5.12 & 4.81 \\
\hline 2 & 6.25 & 1 & 5 & 70.05 & 70.63 & 48.25 & 48.34 & 15.50 & 14.54 \\
\hline 3 & 1.05 & 4 & 5 & 41.5 & 39.97 & 21.35 & 21.46 & 15.75 & 14.16 \\
\hline 4 & 6.25 & 4 & 5 & 58.75 & 58.13 & 35.75 & 35.64 & 36 & 38.18 \\
\hline 5 & 1.05 & 1 & 11 & 40.5 & 41.57 & 27 & 27.02 & 3.21 & 3.18 \\
\hline 6 & 6.25 & 1 & 11 & 60.15 & 62.13 & 38.5 & 38.30 & 10 & 10.58 \\
\hline 7 & 1.05 & 4 & 11 & 34.4 & 34.27 & 18.25 & 18.06 & 9.5 & 9.46 \\
\hline 8 & 6.25 & 4 & 11 & 50 & 49.03 & 28.5 & 28.54 & 35 & 34.30 \\
\hline 9 & 1.05 & 2.5 & 8 & 50.5 & 49.68 & 39 & 39.20 & 4.5 & 5.0 \\
\hline 10 & 6.25 & 2.5 & 8 & 70 & 69.04 & 51.75 & 51.93 & 28 & 26.91 \\
\hline 11 & 3.65 & 1 & 8 & 73.5 & 68.46 & 46 & 46.23 & 16.15 & 20.02 \\
\hline 12 & 3.65 & 4 & 8 & 55.3 & 58.56 & 35.25 & 35.40 & 36.4 & 36.56 \\
\hline 13 & 3.65 & 2.5 & 5 & 60 & 60.16 & 42 & 42.05 & 28 & 28.68 \\
\hline 14 & 3.65 & 2.5 & 11 & 55 & 53.06 & 35 & 35.33 & 21 & 24.35 \\
\hline 15 & 3.65 & 2.5 & 8 & 64 & 64.59 & 47 & 46.87 & 30 & 28.66 \\
\hline 16 & 3.65 & 2.5 & 8 & 64 & 64.59 & 47 & 46.87 & 30 & 28.66 \\
\hline 17 & 3.65 & 2.5 & 8 & 64 & 64.59 & 47 & 46.87 & 30 & 28.66 \\
\hline 18 & 3.65 & 2.5 & 8 & 64 & 64.59 & 47 & 46.87 & 30 & 28.66 \\
\hline 19 & 3.65 & 2.5 & 8 & 64 & 64.59 & 47 & 46.87 & 30 & 28.66 \\
\hline 20 & 3.65 & 2.5 & 8 & 64 & 64.59 & 47 & 46.87 & 30 & 28.66 \\
\hline
\end{tabular}

لودينة الملك عبدالعزيز KACST 
quadratic model regression equations were obtained from Design Expert Software as shown in Eqs. (10), (11) and (12):

$$
\begin{aligned}
Y_{1}= & 64.59+9.68 X_{1}-4.95 X_{2}-3.55 X_{3}-1.45 X_{1} X_{2}-0.85 X_{1} X_{3} \\
& -0.15 X_{2} X_{3}-5.23 X_{1}^{2}-1.08 X_{2}^{2}-7.98 X_{3}^{2}
\end{aligned}
$$

$$
\begin{gathered}
Y_{2}=46.87+6.36 X_{1}-5.42 X_{2}-3.36 X_{3}-0.2 X_{1} X_{2}-0.93 X_{1} X_{3} \\
+0.74 X_{2} X_{3}-1.30 X_{1}^{2}-6.05 X_{2}^{2}-8.18 X_{3}^{2}
\end{gathered}
$$

$Y_{3}=28.66+8.64 X_{1}+8.27 X_{2}-2.17 X_{3}+3.57 X_{1} X_{2}+0.21 X_{1} X_{3}$

$$
+0.02 X_{2} X_{3}-10.39 X_{1}^{2}-0.37 X_{2}^{2}-2.14 X_{3}^{2}
$$

Experimental data were analyzed by sequential model sum of squares and model summary statistics to obtain the most suitable models among various models such as linear, interactive, quadratic and cubic. The results are

\begin{tabular}{|c|c|c|c|c|c|c|}
\hline \multicolumn{7}{|c|}{ Sequential model sum of squares } \\
\hline Source & Sum of square & $d f$ & Mean square & $F$ value & $P$ value & Prob $>F$ \\
\hline Mean vs total & $65,998.56$ & 1 & $65,998.56$ & & & \\
\hline Linear vs mean & 1308.07 & 3 & 436.02 & 7.97 & 0.0018 & \\
\hline 2FI vs linear & 22.78 & 3 & 7.59 & 0.1158 & 0.9492 & \\
\hline Quadratic vs 2FI & 797.58 & 3 & 265.86 & 48.69 & $<0.0001$ & Suggested \\
\hline Cubic vs quadratic & 47.36 & 4 & 11.84 & 9.80 & 0.0084 & Aliased \\
\hline Residual & 7.25 & 6 & 1.21 & & & \\
\hline Total & $68,181.60$ & 20 & 3409.08 & & & \\
\hline \multicolumn{7}{|c|}{ Model summary statistics } \\
\hline Source & Std. dev. & $R^{2}$ & Adjusted $R^{2}$ & Predicted $R^{2}$ & PRESS & \\
\hline Linear & 7.39 & 0.5992 & 0.5240 & 0.2672 & 1599.81 & \\
\hline $2 \mathrm{FI}$ & 8.10 & 0.6096 & 0.4295 & -1.9223 & 6379.45 & \\
\hline Quadratic & 2.34 & 0.9750 & 0.9525 & 0.8068 & 421.76 & Suggested \\
\hline Cubic & 1.10 & 0.9967 & 0.9895 & -3.0784 & 8903.33 & Aliased \\
\hline
\end{tabular}
tabulated in Tables 4, 5 and 6 for the \% color removal, \% TOC removal and power consumption, respectively. From Tables 4, 5 and 6 , it can be seen that quadratic model

Table 4 Sequential model sum of squares and model summary statistics for percentage color removal (\%)

\begin{tabular}{|c|c|c|c|c|c|c|}
\hline Source & Sum of square & $d f$ & Mean square & $F$ value & $P$ value & Prob $>F$ \\
\hline Mean vs total & $30,584.02$ & 1 & $30,584.02$ & & & \\
\hline Linear vs mean & 811.25 & 3 & 270.42 & 4.57 & 0.0170 & \\
\hline 2FI vs linear & 11.52 & 3 & 3.84 & 0.0534 & 0.9830 & \\
\hline Quadratic vs 2FI & 934.10 & 3 & 311.37 & 6249.77 & $<0.0001$ & Suggested \\
\hline Cubic vs quadratic & 0.1545 & 4 & 0.0386 & 0.6743 & 0.6338 & Aliased \\
\hline Residual & 0.3437 & 6 & 0.0573 & & & \\
\hline Total & $32,341.39$ & 20 & 1617.07 & & & \\
\hline \multicolumn{7}{|c|}{ Model summary statistics } \\
\hline Source & Std. dev. & $R^{2}$ & Adjusted $R^{2}$ & Predicted $R^{2}$ & PRESS & \\
\hline Linear & 7.69 & 0.4616 & 0.3607 & 0.0406 & 1685.96 & \\
\hline $2 \mathrm{FI}$ & 8.48 & 0.4682 & 0.2227 & -2.8880 & 6832.70 & \\
\hline Quadratic & 0.2232 & 0.9997 & 0.9995 & 0.9976 & 4.22 & Suggested \\
\hline Cubic & 0.2393 & 0.9998 & 0.9994 & 0.7597 & 422.31 & Aliased \\
\hline
\end{tabular}

$d f$ degree of freedom

Table 5 Sequential model sum of squares and model summary statistics for percentage TOC removal (\%)

Sequential model sum of squares

$d f$ degree of freedom 
Table 6 Sequential model sum of squares and model summary statistics for power consumption, $\mathrm{kWhr} / \mathrm{m}^{3}$

Sequential model sum of squares

\begin{tabular}{|c|c|c|c|c|c|c|}
\hline Source & Sum of square & $d f$ & Mean square & $F$ value & $P$ value & Prob $>F$ \\
\hline Mean vs total & 9862.57 & 1 & 9862.57 & & & \\
\hline Linear vs mean & 1477.19 & 3 & 492.40 & 8.64 & 0.0012 & \\
\hline 2FI vs linear & 102.45 & 3 & 34.15 & 0.5488 & 0.6577 & \\
\hline Quadratic vs 2FI & 724.69 & 3 & 241.56 & 28.69 & $<0.0001$ & Suggested \\
\hline Cubic vs quadratic & 47.00 & 4 & 11.75 & 1.89 & 0.2308 & Aliased \\
\hline Residual & 37.22 & 6 & 6.20 & & & \\
\hline Total & $12,251.11$ & 20 & 612.56 & & & \\
\hline \multicolumn{7}{|c|}{ Model summary statistics } \\
\hline Source & Std. Dev. & $R^{2}$ & Adjusted $R^{2}$ & Predicted $R^{2}$ & PRESS & \\
\hline Linear & 7.55 & 0.6184 & 0.5469 & 0.3484 & 1556.40 & \\
\hline $2 \mathrm{FI}$ & 7.89 & 0.6613 & 0.5050 & -0.9141 & 4571.90 & \\
\hline Quadratic & 2.90 & 0.9647 & 0.9330 & 0.8584 & 672.72 & Suggested \\
\hline Cubic & 2.49 & 0.9844 & 0.9507 & -18.1442 & $45,726.80$ & Aliased \\
\hline
\end{tabular}

$d f$ degree of freedom

gives the highest $R^{2}$, adjusted $R^{2}$ and predicted $R^{2}$ values when compared to the other models after excluding the cubic model. The cubic model cannot be used for further modeling of experimental data because it was found to be aliased. An aliased model was a result of insufficient experiments run to independently estimate all the terms of the model. Thus, not all parameters can be estimated and it is unwise for further studying an aliased model. The highest order polynomial from the sequential model sum of squares, quadratic model, was selected for modeling the treatment of landfill leachate using electrocoagulation process where the additional terms are significant and the model is not aliased.

\section{Adequacy of the model tested for \% color removal, $\%$ TOC removal and power consumption}

The significance and adequacy of the model was analyzed by the analysis of variance (ANOVA) and the results for $\%$ color removal, \% TOC removal and power consumption are given in Tables 7, 8 and 9, respectively. The $F$ test of the quadratic models gives a small $P$ value $(<0.05)$, which indicates that all the models were significant and could be used to predict the outcome for the electrocoagulation process. From Table 7, it can be seen that for the \% of color removal, the linear coefficient of the current density $\left(X_{1}\right)$, inter-electrode distance $\left(X_{2}\right)$ and initial $\mathrm{pH}\left(X_{3}\right)$
Table 7 ANOVA of the secondorder polynomial equation for percentage color removal, (\%)

\begin{tabular}{lcrlcll}
\hline Source & Sum of squares & $d f$ & Mean square & $F$ value & $P$ value & Prob $>F$ \\
\hline Model & 2128.44 & 9 & 236.49 & 43.31 & $<0.0001$ & Highly significant \\
$X_{1}$ & 937.02 & 1 & 937.02 & 171.61 & $<0.0001$ & Highly significant \\
$X_{2}$ & 245.03 & 1 & 245.03 & 44.87 & $<0.0001$ & Highly significant \\
$X_{3}$ & 126.03 & 1 & 126.03 & 23.08 & 0.0007 & Significant \\
$X_{1} X_{2}$ & 16.82 & 1 & 16.82 & 3.08 & 0.1098 & \\
$X_{1} X_{3}$ & 5.78 & 1 & 5.78 & 1.06 & 0.3278 & \\
$X_{2} X_{3}$ & 0.1800 & 1 & 0.1800 & 0.0330 & 0.8596 & \\
$X_{1}^{2}$ & 75.27 & 1 & 75.27 & 13.79 & 0.0040 & Significant \\
$X_{2}^{2}$ & 3.22 & 1 & 3.22 & 0.5894 & 0.4604 & \\
$X_{3}^{2}$ & 175.20 & 1 & 175.20 & 32.09 & 0.0002 & Significant \\
Residual & 54.60 & 10 & 5.46 & & & \\
Lack of fit & 54.60 & 5 & 10.92 & & & \\
Pure error & 0.0000 & 5 & 0.0000 & & & \\
Cor total & 2183.04 & 19 & & & & \\
\hline
\end{tabular}

$d f$ degree of freedom 
Table 8 ANOVA of the secondorder polynomial equation for percentage TOC removal $(\%)$
Table 9 ANOVA of the secondorder polynomial equation for power consumption, $\left(\mathrm{kWhr} / \mathrm{m}^{3}\right)$

\begin{tabular}{lcrlrrl}
\hline Source & Sum of squares & $d f$ & Mean square & $F$ value & $P$ value & Prob $>F$ \\
\hline Model & 1756.87 & 9 & 195.21 & 3918.22 & $<0.0001$ & Highly significant \\
$X_{1}$ & 405.13 & 1 & 405.13 & 8131.85 & $<0.0001$ & Highly significant \\
$X_{2}$ & 293.22 & 1 & 293.22 & 5885.58 & $<0.0001$ & Highly significant \\
$X_{3}$ & 112.90 & 1 & 112.90 & 2266.06 & $<0.0001$ & Highly significant \\
$X_{1} X_{2}$ & 0.3200 & 1 & 0.3200 & 6.42 & 0.0296 & Significant \\
$X_{1} X_{3}$ & 6.84 & 1 & 6.84 & 137.39 & $<0.0001$ & Highly significant \\
$X_{2} X_{3}$ & 4.35 & 1 & 4.35 & 87.34 & $<0.0001$ & Highly significant \\
$X_{1}^{2}$ & 4.66 & 1 & 4.66 & 93.61 & $<0.0001$ & Highly significant \\
$X_{2}^{2}$ & 100.73 & 1 & 100.73 & 2021.91 & $<0.0001$ & Highly significant \\
$X_{3}^{2}$ & 183.89 & 1 & 183.89 & 3690.98 & $<0.0001$ & Highly significant \\
Residual & 0.4982 & 10 & 0.0498 & & & \\
Lack of fit & 0.4982 & 5 & 0.0996 & & & \\
Pure error & 0.0000 & 5 & 0.0000 & & & \\
Cor total & 1757.36 & 19 & & & & \\
\hline
\end{tabular}

$d f$ degree of freedom

\begin{tabular}{lcccccl}
\hline Source & Sum of squares & $d f$ & Mean square & $F$ value & $P$ value & Prob $>F$ \\
\hline Model & 2304.33 & 9 & 256.04 & 30.40 & $<0.0001$ & Highly significant \\
$X_{1}$ & 746.84 & 1 & 746.84 & 88.69 & $<0.0001$ & Highly significant \\
$X_{2}$ & 683.43 & 1 & 683.43 & 81.16 & $<0.0001$ & Highly significant \\
$X_{3}$ & 46.92 & 1 & 46.92 & 5.57 & 0.0399 & Significant \\
$X_{1} X_{2}$ & 102.10 & 1 & 102.10 & 12.12 & 0.0059 & Significant \\
$X_{1} X_{3}$ & 0.3445 & 1 & 0.3445 & 0.0409 & 0.8438 & \\
$X_{2} X_{3}$ & 0.0032 & 1 & 0.0032 & 0.0004 & 0.9848 & \\
$X_{1}^{2}$ & 296.97 & 1 & 296.97 & 35.26 & 0.0001 & Significant \\
$X_{2}^{2}$ & 0.3700 & 1 & 0.3700 & 0.0439 & 0.8382 & \\
$X_{3}^{2}$ & 12.62 & 1 & 12.62 & 1.50 & 0.2490 & \\
Residual & 84.21 & 10 & 8.42 & & & \\
Lack of fit & 84.21 & 5 & 16.84 & & & \\
Pure error & 0.0000 & 5 & 0.0000 & & & \\
Cor total & 2388.54 & 19 & & & &
\end{tabular}

$d f$ degree of freedom

and the quadratic coefficient of current density $\left(X_{1}^{2}\right)$ and initial $\mathrm{pH}\left(X_{3}^{2}\right)$ were significant, with $\mathrm{p}$ value less than 0.05 . For the $\%$ TOC removal, it can be observed from Table 8 that the linear coefficient of current density $\left(X_{1}\right)$, inter-electrode distance $\left(X_{2}\right)$, initial $\mathrm{pH}\left(\mathrm{X}_{3}\right)$, interaction effect of current density $\left(X_{1}\right)$ with inter-electrode distance $\left(X_{2}\right)$, current density $\left(X_{1}\right)$ with initial $\mathrm{pH}\left(X_{3}\right)$ and interelectrode distance $\left(X_{2}\right)$ with initial $\mathrm{pH}\left(X_{3}\right)$ and quadratic coefficient of current density $\left(X_{1}\right)$, inter-electrode distance $\left(X_{2}^{2}\right.$ and initial $\mathrm{pH}\left(X_{3}^{2}\right)$ were significant variables. For the power consumption from Table 9, the linear effect of current density $\left(X_{1}\right)$, inter-electrode distance $\left(X_{2}\right)$ and initial $\mathrm{pH}\left(X_{3}\right)$, interaction effect of current density $\left(X_{1}\right)$ with inter-electrode distance $\left(\mathrm{X}_{2}\right)$ and the quadratic effect of the current density $\left(X_{1}^{2}\right)$ were found to be significant. "Adeq Precision" measures the signal-to-noise ratio; it was desirable to obtain a value greater than 4 . The signal-to-noise ratio was $22.01,214.61$ and 18.60 which is greater than 4 for the \% color removal, \% TOC removal and power consumption, respectively. Thus, the second-order model can be used to navigate the design space. Adequacy check is crucial to make sure the approximation model can give adequate approximation to prevent poor and misleading result. 

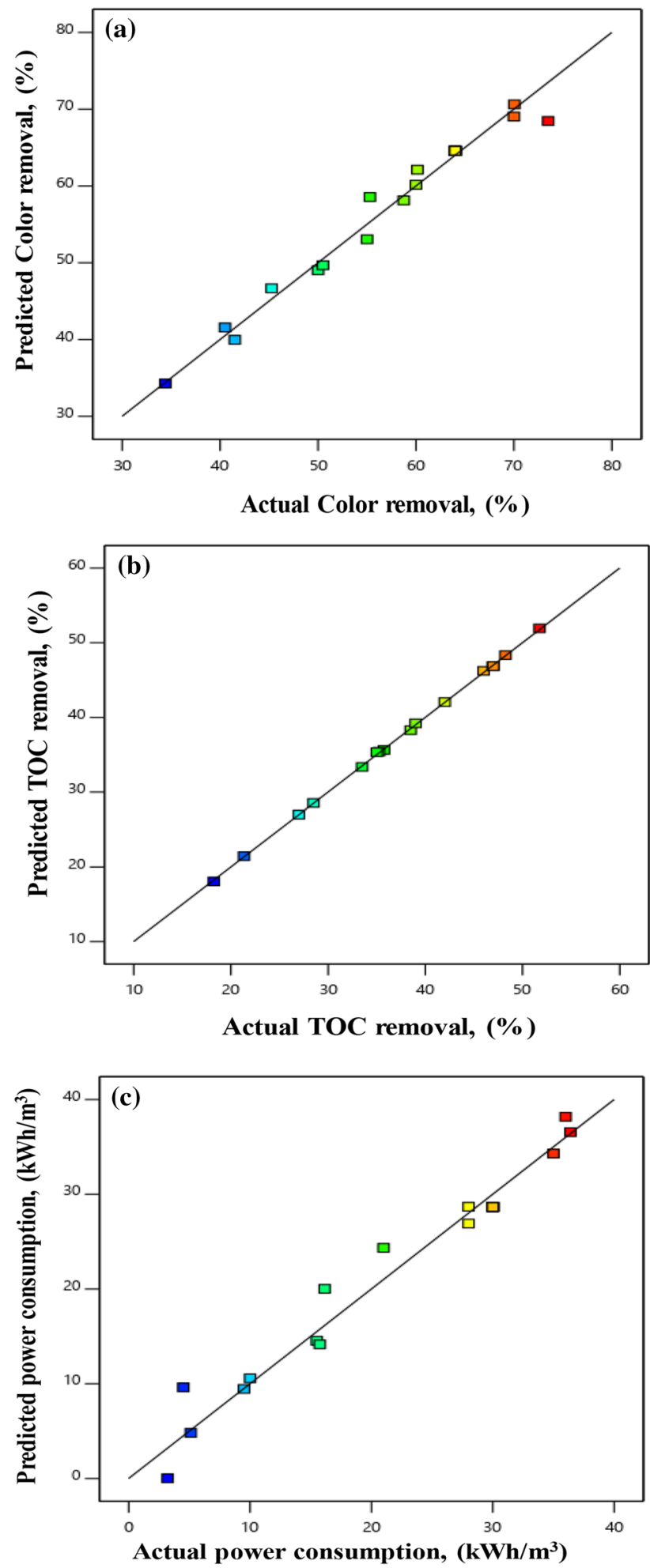

Fig. 2 Plot for relationship between experimental and predicted value for a $\%$ color removal, b $\%$ TOC removal and c power consumption

\section{Experimental versus predicted}

The comparison between experimental and predicted value is shown in Table 3 and Fig. 2a-c. From Fig. 2, it can be seen that the model-predicted values matched the experimental data in which all the points are closed to the diagonal line. The ANOVA analysis showed that all the three quadratic models were significant $(p<0.05)$ and can be used to predict the $\%$ of color removal, $\%$ TOC removal, and also power consumption. The quality of predicted points was verified by the $R^{2}$ value, where the $R^{2}$ values were 0.97 , 0.99 and 0.96 for \% of color removal, \% TOC removal and power consumption, respectively.

\section{Combined effect of operating parameters for \% color removal, \% TOC removal and power consumption}

The effect of operating parameters in estimating the maximum \% color removal, \% TOC removal and minimum of power consumption with respect to each variable and the impact of each operating parameter on the output are discussed as following. The electrolysis time for the electrocoagulation process was $1 \mathrm{~h}$ and the initial COD concentration of the leachate is diluted to $1500 \mathrm{ppm}$ to visualize a better and clearer result.

\section{Combined effect of current density $\left(X_{1}\right)$ and inter-electrode distance $\left(X_{2}\right)$}

The combined effect of current density $\left(X_{1}\right)$ and inter-electrode distance $\left(X_{2}\right)$ on \% color and \% TOC removal with power consumption was tested by varying $X_{1}$ from 1.05 to $6.25 \mathrm{~A} / \mathrm{dm}^{2}$ and $X_{2}$ from 1 to $4 \mathrm{~cm}$ and the results are tabulated in Table 3 and plotted in Fig. 3a-c. From Fig. 3a, b, it can be observed that the \% color removal and \% TOC removal were increased as the current density increased, but after the optimum value, further increase in current density does not help in improving the removal of $\%$ color and TOC (Kalyani et al. 2009). The increase in current density resulted in the production of large amount of $\mathrm{Al}^{3+}$ ions via anodic metal dissolution, more $\mathrm{H}_{2}$ bubbles was formed at the cathode, which are profitable for the separation or flotation process (Ozyonar and Karagozoglu 2015). From Fig. 3c, it can be seen that the increase in current density caused an increase in the power consumption. This is because, an increase in current density caused an increase in cell voltage, which had a direct impact on the power consumption of the electrochemical process. Since a proportional relationship was established between the current density and power consumption, it is necessary to identify the optimum value of current density to reduce the power consumption and operating cost (Heidmann and Calmano 2008). 
(a)

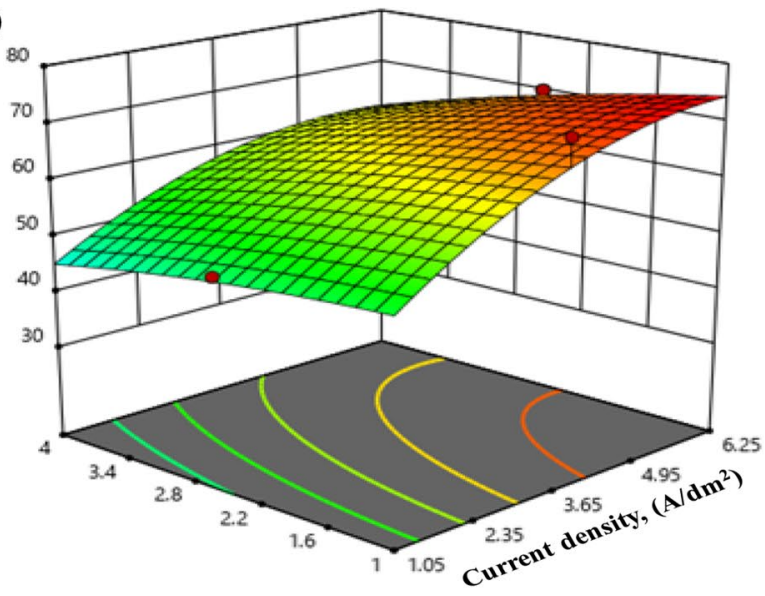

(b)

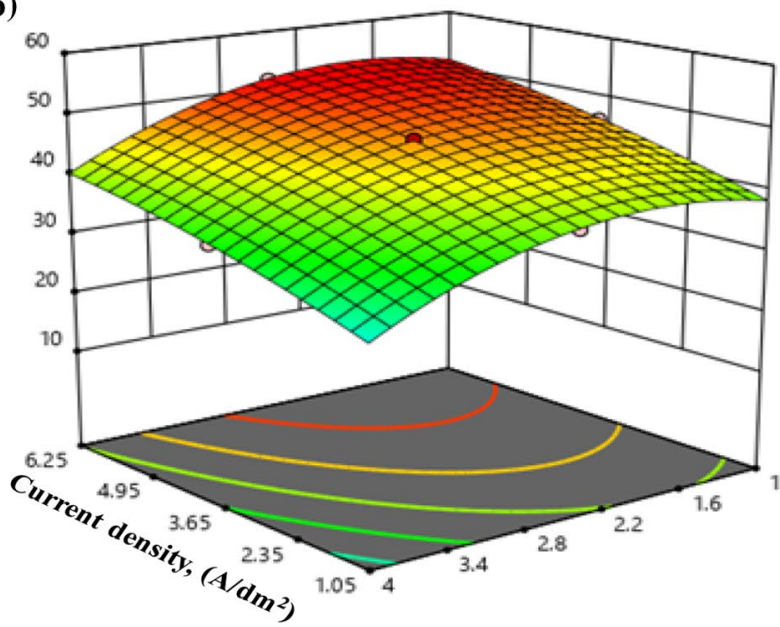

(c)

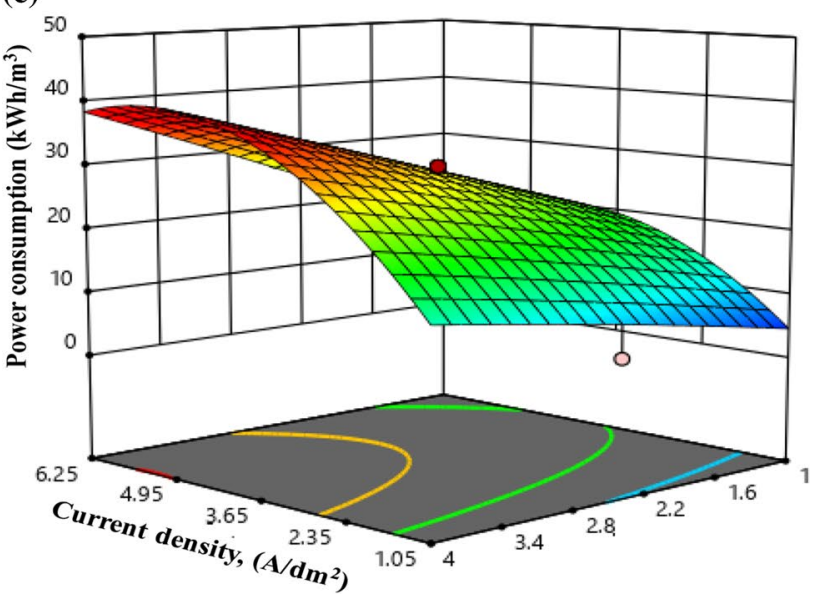

Fig. 3 Combined effect of current density $\left(X_{1}\right)$ and inter-electrode distance $\left(X_{2}\right)$ on a $\%$ color removal, b \% TOC removal and $\mathbf{c}$ power consumption

Inter-electrode distance $\left(X_{2}\right)$ was varied from 1 to $4 \mathrm{~cm}$ in order to study its effect on the \% color removal, \% TOC removal and power consumption. From Fig. 3a, b, it was seen that the $\%$ color removal and $\%$ TOC removal was decreased as the inter-electrode distance increased from 1 to $4 \mathrm{~cm}$ at any value of current density in the range of 1.05-6.25 A/ $\mathrm{dm}^{2}$. This is because there is an increased in ohmic voltage drop as the distance between the anode and cathode was increased (Khandegar and Saroha 2013). Besides, Faraday's law also stated that the amount of oxidized metal decreased as the gap between the electrodes was increased. However, Fig. $3 \mathrm{c}$ shows that the power consumption increased as the inter-electrode distance increased. This was due to the fact that there is more resistance offered when the electrodes gap increase and power consumption is directly proportional to the cell voltage (Ricordel and Djelal 2014).

\section{Combined effect of initial pH $\left(X_{3}\right)$ and current density $\left(X_{1}\right)$}

Initial $\mathrm{pH}$ of the landfill leachate $\left(X_{3}\right)$ was adjusted in the range of $\mathrm{pH} 5-11$ to investigate the impact of the $\mathrm{pH}$ on the $\%$ color removal, $\%$ TOC removal and power consumption. The result is given in Table 3 and plotted in Fig. 4a-c. From Fig. $4 a$, b, it can be seen that the $\%$ color and $\%$ TOC removal were increased at effluent $\mathrm{pH}$ from 5 to 7.5 ; however, further increase in $\mathrm{pH}$ from 7.5 to 11 decreased the removal efficiency. This can be explained by the formation of aluminium species formed in the reaction. For the $\mathrm{Al}$ electrodes in acidic medium, monomeric hydroxometallic cation $\mathrm{Al}(\mathrm{OH})_{3}$ is formed. At neutral medium, both polymeric hydroxometallic cations and metal hydroxides precipitates coexist while at higher $\mathrm{pH}$ or alkali medium, the net charge on the surface of the amorphous metal hydroxide precipitate changes from positive to negative and the polymeric cations will only remain in the solution. More ${ }^{\bullet} \mathrm{OH}$ can be formed in neutral condition compared to acidic and alkaline mediums in the electrocoagulation process (Modirshahla et al. 2007; Kobya et al. 2003). However, from Fig. 4c, it can be seen that the initial $\mathrm{pH}$ of the leachate had no impact on the power consumption for the electrocoagulation process. This is because the conductivity of the landfill leachate did not change as a result of $\mathrm{pH}$ adjustment; thus, $3 \mathrm{~g} / \mathrm{L}$ of $\mathrm{NaCl}$ or mediator has been added in before starting the experiment.

\section{Optimization}

The main objective of this study is to determine the optimal operating parameters for the maximum $\%$ color and $\%$ TOC removal with the minimum of power consumption from landfill leachate wastewater using the electrocoagulation process. The results were optimized using the regression equation of RSM based on CCD. While optimizing, all the input variables such as current density $\left(X_{1}\right)$, inter-electrode distance $\left(X_{2}\right)$ and initial $\mathrm{pH}\left(X_{3}\right)$ were selected as within the range while the output variables such as \% color removal and $\%$ TOC removal were maximized with power consumption 


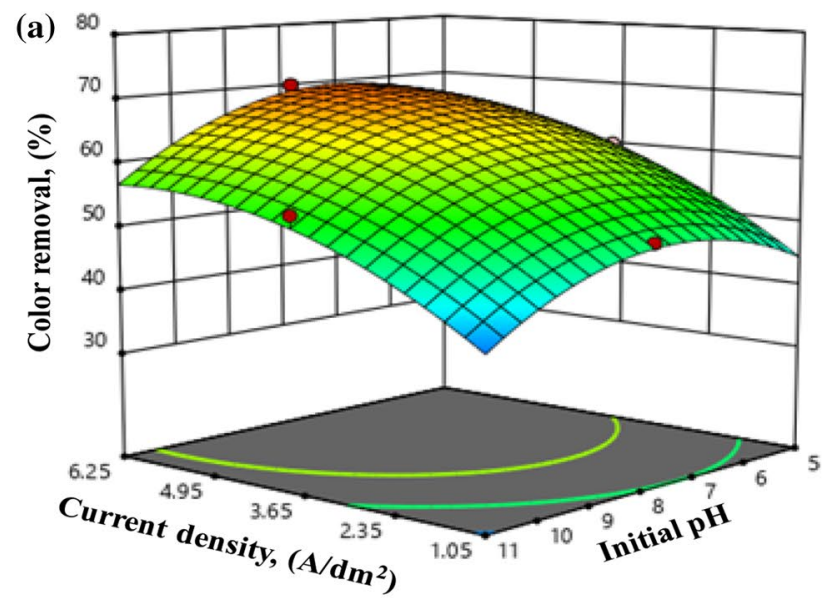

(b)

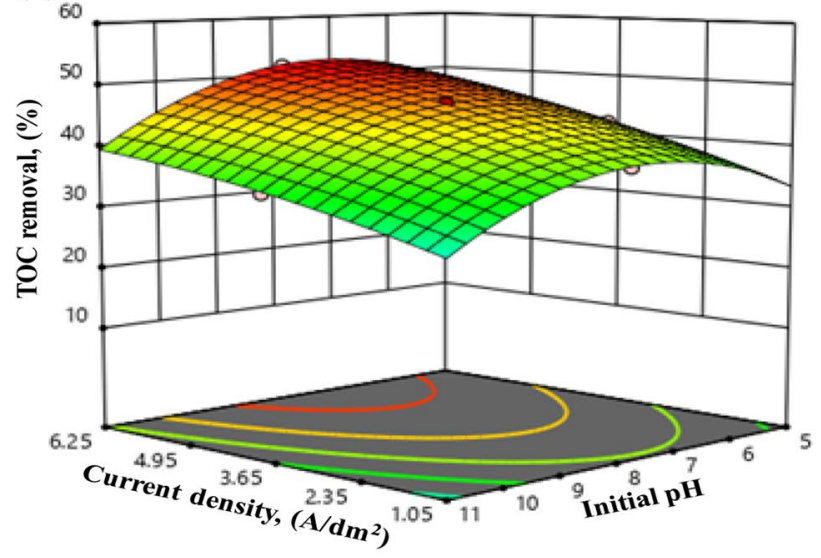

(c)

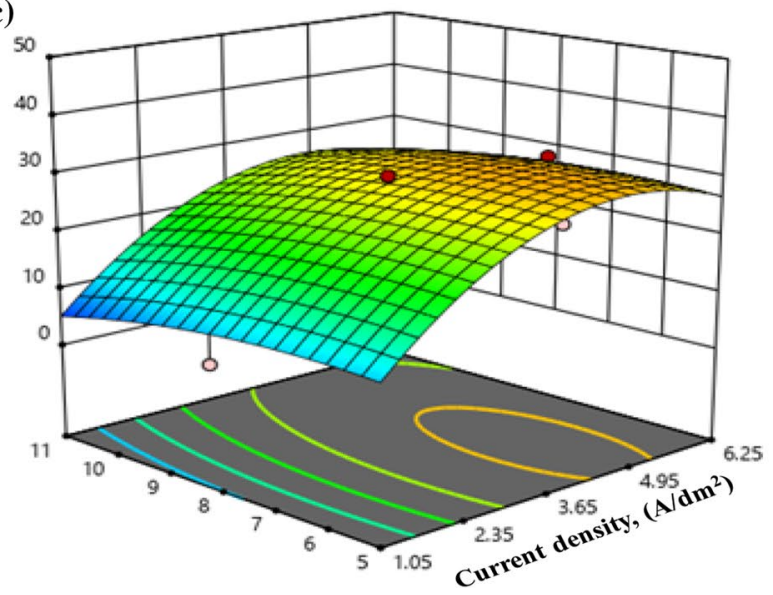

Fig. 4 Combined effect of initial $\mathrm{pH}\left(X_{3}\right)$ and current density $\left(X_{1}\right)$ on a $\%$ color removal, b \% TOC removal and $\mathbf{c}$ power consumption

minimized. The optimized operating parameters are as following: current density $\left(X_{1}\right)-5.25 \mathrm{~A} / \mathrm{dm}^{2}$, inter-electrode distance $\left(X_{2}\right)-1 \mathrm{~cm}$ and initial $\mathrm{pH}\left(X_{3}\right)-7.83$ with expected result of color removal to be $74.57 \%$, TOC removal of $51.74 \%$ and $14.80 \mathrm{kWh} / \mathrm{m}^{3}$ for power consumption. A mean value of $75.20 \%$ for color removal, $50.90 \%$ for TOC removal and $13.75 \mathrm{kWh} / \mathrm{m}^{3}$ for power consumption was obtained

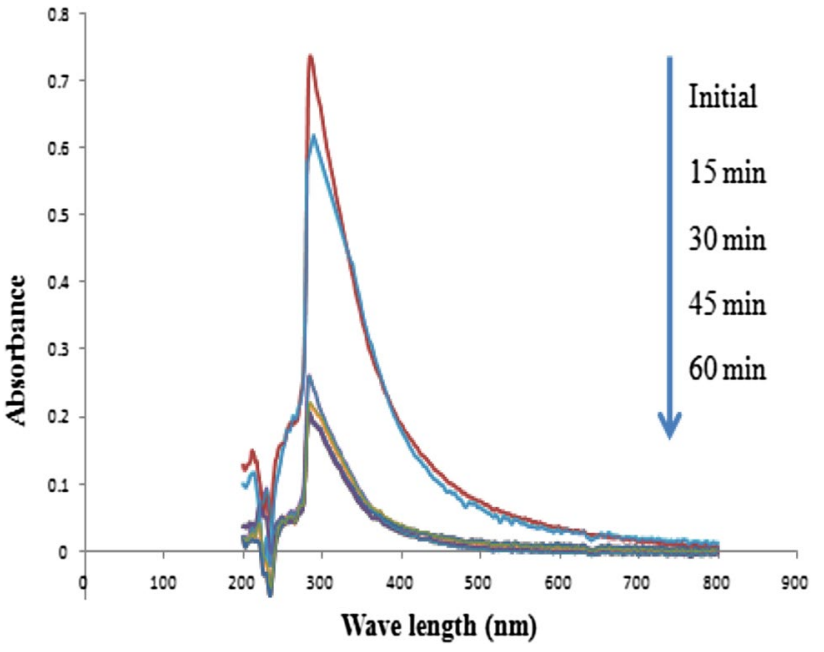

Fig. 5 Spectra of landfill leachate wastewater, recorded before and after the electrocoagulation process at different electrolysis times

experimentally, which is closed to the predicted result. From the expected and actual result, it can be said that there was good correlation between them which indicates that the central composite design could be effectively used to optimize the electrocoagulation process parameters.

\section{Instrumental analysis}

The absorption spectra of before and after treatment of electrocoagulation process were analyzed using the UV/Vis spectrophotometer (Spectroquant Pharo ${ }^{\circledR} 300$ ) to study the color removal rate from landfill leachate wastewater. The absorbance spectrum for the landfill leachate effluent had an absorbance peak at $284 \mathrm{~nm}$ which belongs to the coloring agent. From Fig. 5, it can be seen that there was reduction in absorbance of peak with increasing electrolysis time. It might be attributed that, the color of the landfill leachate wastewater was continuously reduced with increasing electrochemical reaction time.

\section{Conclusion}

This study investigated the removal of $\%$ color and $\%$ TOC using electrocoagulation process in a real landfill leachate wastewater. An empirical relationship between the output and independent variables was obtained based on the experimental data and it was expressed by the quadratic model using RSM. The results showed that, the maximum $\%$ color removal, \% TOC removal and minimum of power consumption were $74.57,51.75$ and $14.80 \mathrm{kWh} / \mathrm{m}^{3}$, respectively, obtained at the optimum conditions of current density $\left(X_{1}\right)$ of $5.25 \mathrm{~A} / \mathrm{dm}^{2}$, inter-electrode distance $\left(X_{2}\right)$ of $1 \mathrm{~cm}$ 
and initial effluent $\mathrm{pH}$ of 7.83. Based on the experimental results, an empirical relationship between the response and independent variables was obtained and expressed by the second-order polynomial equation. The ANOVA analysis showed a high coefficient of determination value, thus ensuring a satisfactory adjustment of the second-order regression model with the experimental data. This technology could be used effectively for the removal of pollutants from industrial effluents and wastewater.

Open Access This article is distributed under the terms of the Creative Commons Attribution 4.0 International License (http://creativeco mmons.org/licenses/by/4.0/), which permits unrestricted use, distribution, and reproduction in any medium, provided you give appropriate credit to the original author(s) and the source, provide a link to the Creative Commons license, and indicate if changes were made.

\section{References}

Adlan MN, Palaniandy P, Aziz HA (2011) Optimization of coagulation and dissolved air flotation (DAF) treatment of semi-aerobic landfill leachate using response surface methodology (RSM). Desalination 277(1-3):74-82

Ahn WY, Kang MS, Yim SK, Choi KH (2002) Advanced landfill leachate treatment using an integrated membrane process. Desalination 149(1-3):109-114

Azni I (2009) What is the choice: land disposal or biofuel? In: Waste Management. Universiti Putra Malaysia, pp 1-65. http://dx.doi. org/10.1016/S0026-0576(96)94124-0

Butler EB, Hung YT, Mulamba O (2017) The effects of chemical coagulants on the decolorization of dyes by electrocoagulation using response surface methodology (RSM). Appl Water Sci 7:2357-2371

Chopra AK, Sharma AK (2013) Removal of turbidity, COD and BOD from secondarily treated sewage water by electrolytic treatment. Appl Water Sci 3:125-132

Chys M, Declerck W, Audenaert WTM, Van Hullea SWH (2015) $\mathrm{UV} / \mathrm{H}_{2} \mathrm{O}_{2}, \mathrm{O}_{3}$ and (photo-) Fenton as treatment prior to granular activated carbon filtration of biologically stabilized landfill leachate. J Chem Technol Biotechnol 90:525-533

Derco J, Gotvajn AZ, Zagorc-Koncan J (2010) Pretreatment of landfill leachate by chemical oxidation processes. Chem Pap 64(2):237-245

Erabee IK, Ahsan A, Jose B, Manniruzzaman M, Aziz A, Ng AWM, Idrus S, Daud NNN (2017) Adsorptive treatment of landfill leachate using activated carbon modified with three different methods. KSCE J Civ Eng. https://doi.org/10.1007/s1220 5-017-1430-Z

Fernandes A, Pacheco MJ, Ciríaco L, Lopes A (2015) Review on the electrochemical processes for the treatment of sanitary landfill leachates: present and future. App Catal B 76-177:183-200

Heidmann I, Calmano W (2008) Removal of Cr(VI) from model wastewaters by electrocoagulation with Fe electrodes. Sep Purif Technol 61(1):15-21

Hu X, Wang X, Ban Y, Ren B (2011) A comparative study of UVFenton, $\mathrm{UV}-\mathrm{H}_{2} \mathrm{O}_{2}$ and Fenton reaction treatment of landfill leachate. Environ Tech 32(9):945-951

Hur JM, Kim SH (2000) Combined adsorption and Chemical precipitation process for pretreatment or post-treatment of landfill leachate. Korean J Chem Eng 17:433-437
Iskander SM, Zou S, Brazil B, Novak JT, He Z (2017) Energy consumption by forward osmosis treatment of landfill leachate for water recovery. Waste Manage 63:284-291

Janpoor F, Torabian A, Khatibikamal V (2011) Treatment of laundry waste-water by electrocoagulation. J Chem Technol Biotechnol 86:1113-1120

Juttner K, Galla U, Schmieder H (2000) Electrochemical approaches to environmental problems in the process industry. Electrochim Acta 45(15-16):2575-2594

Kalyani KSP, Balasubramanian N, Srinivasakannan C (2009) Decolorization and COD reduction of paper industrial effluent using electro-coagulation. Chem Eng J 151(1-3):97-104

Khandegar V, Saroha AK (2013) Electrocoagulation for the treatment of textile industry effluent - a review. J Environ Manage 128:949-963

Kobya M, Can OT, Bayramoglu M (2003) Treatment of textile wastewaters by electrocoagulation using iron and aluminum electrodes. J Hazard Mater 100(1-3):163-178

Li X, Song J, Guo J, Wang Z, Feng Q (2011) Landfill leachate treatment using electrocoagulation. Proc Environ Sci 10:1159-1164

Li YL, Wang J, Yue ZB, Tao W, Yang HB, Zhou YF, Chen TH (2017) Simultaneous chemical oxygen demand removal, methane production and heavy metal precipitation in the biological treatment of landfill leachate using acid mine drainage as sulfate resource. J Biosci Bioeng 124(1):71-75

Liu X, Li XM, Yang Q, Yue X, Shen TT, Zheng W, Zeng GM (2012) Landfill leachate pretreatment by coagulation-flocculation process using iron-based coagulants: optimization by response surface methodology. Chem Eng J 200-202:39-51

Modirshahla N, Behnajady MA, Kooshaiian S (2007) Investigation of the effect of different electrode connections on the removal efficiency of Tartrazine from aqueous solutions by electrocoagulation. Dyes Pigm 74(2):249-257

Moreno-Casillas HA, Cocke DL, Gomes JAG, Morkovsky P, Parga JR, Peterson E (2007) Electrocoagulation mechanism for COD removal. Sep Purif Technol 56(2):204-211

Ozyonar F, Karagozoglu B (2015) Treatment of pretreated coke wastewater by electrocoagulation and electrochemical peroxidation processes. Sep Purif Technol 150:268-277

Panizza M, Delucchi M, Sires I (2010) Electrochemical process for the treatment of landfill leachate. J Appl Electrochem 40:1721-1727

Ricordel C, Djelal H (2014) Treatment of landfill leachate with high proportion of refractory materials by electrocoagulation: system performances and sludge settling characteristics. J Environ Chem Eng 2(3):1551-1557

Robinson T (2017) Removal of toxic metals during biological treatment of landfill leachates. Waste Manage 63:299-309

Saravanan M, Pabmanavhan Sambhamurthy N, Sivarajan M (2010) Treatment of Acid Blue 113 Dye Solution Using Iron Electrocoagulation. CLEAN Soil Air Water 38(5-6):565-571

Sharma AK, Chopra AK (2017) Removal of nitrate and sulphate from biologically treated municipal wastewater by electrocoagulation. Appl Water Sci 7:1239-1246

Vallejo M, San Román MF, Irabien A, Ortiz I (2012) Comparative study of the destruction of polychlorinated dibenzo-p-dioxins and dibenzofurans during Fenton and electrochemical oxidation of landfill leachates. Chemosphere 90(1):132-138

Wang CT, Chou WL, Kuo YM (2009) Removal of COD from laundry wastewater by electrocoagulation/electroflotation. J Hazard Mater 164(1):81-86

Wang C, Alpatova A, McPhedran KN, Gamal El-Din M (2015) Coagulation/flocculation process with polyaluminum chloride for the remediation of oil sands process-affected water: performance and mechanism study. J Environ Manage 160:254-262

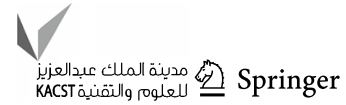


Zhang H, Wu X, Li X (2012) Oxidation and coagulation removal of COD from landfill leachate by Fered-Fenton process. Chem Eng J 210:188-194

Zhang DB, Wu XG, Wang Hui YS, Zhang H (2014) Landfill leachate treatment using the sequencing batch biofilm reactor method integrated with the electro-Fenton process. Chem Pap 68(6):782-787

Zhang D, Vahala R, Wang Y, Smets BF (2016) Microbes in biological processes for municipal landfill leachate treatment: community, function and interaction. Int Biodeterior Biodegradation 113:88-96
Zodi S, Potier O, Lapicque F, Leclerc JP (2009) Treatment of the textile wastewaters by electrocoagulation: effect of operating parameters on the sludge settling characteristics. Sep and Purif Technol 69(1):29-36

Publisher's Note Springer Nature remains neutral with regard to jurisdictional claims in published maps and institutional affiliations. 